\title{
The contribution of the swallowed fraction of an inhaled dose of salmeterol to it systemic effects
}

\author{
J.A. Bennett, T.W. Harrison, A.E. Tattersfield
}

The contribution of the swallowed fraction of an inhaled dose of salmeterol to it systemic effects. J.A. Bennett, T.W. Harrison, A.E. Tattersfield. (C) ERS Journals Ltd 1999.

ABSTRACT: Salmeterol is approximately eight times as potent as salbutamol for systemic effects. This may be because the drug is eight times more potent on receptors or there may be differences in systemic bioavailability. The systemic effects of salbutamol are limited by its fairly high first-pass metabolism, but the oral bioavailability of salmeterol is unknown. The contribution of the swallowed fraction of an inhaled dose of salmeterol to its systemic effects were analysed in a randomized, double-blind, crossover study.

Twelve healthy subjects were given inhaled salmeterol $400 \mu \mathrm{g}$, inhaled salmeterol $400 \mu \mathrm{g}$ plus oral activated charcoal or inhaled placebo plus oral activated charcoal on three separate days. Cardiac frequency $(f \mathrm{C})$, Q-T interval corrected for heart rate (QTe), plasma potassium and glucose concentrations were measured for $\mathbf{4} \mathrm{h}$ following the inhaled drug.

Salmeterol with and without oral charcoal produced significant changes for all measures compared to placebo. The magnitude of effect following salmeterol alone was significantly greater than that following salmeterol plus charcoal for $f \mathrm{C}$ and glucose (mean $\left(95 \%\right.$ confidence interval) differences $8(2-13)$ beats $\min ^{-1}, 0.59(0.04$, 1.13) $\mathbf{m m o l} \cdot \mathrm{L}^{-1}$, respectively) and nonsignificantly greater for QTe interval and potassium concentration.

The differences between salmeterol given with and without charcoal suggest that $28-36 \%$ of the systemic response to salmeterol administered from a metered-dose inhaler are due to drug absorbed from the gastrointestinal tract. Thus, most of the systemic effects are due to the inhaled fraction of the drug.

Eur Respir J 1999; 13: 445-448.

In previous studies in which the authors compared $\beta_{2-}$ adrenoceptor-mediated systemic effects, salmeterol was roughly eight-fold more potent than salbutamol, weight for weight [1-3]. The difference may be due to differences in potency on $\beta$-receptors and/or differences in pharmacokinetic properties of the two drugs. There are no published data on the pharmacokinetic profile of salmeterol and no data on the extent to which inhaled salmeterol undergoes first-pass metabolism. Activated charcoal has been shown to prevent the absorption of oral salmeterol from the gastrointestinal tract [4]. The systemic responses following a high-dose of inhaled salmeterol $(400 \mu \mathrm{g})$ given with and without oral activated charcoal were therefore compared to determine the contribution of the swallowed fraction of an inhaled dose of salmeterol to its systemic effects.

\section{Methods}

\section{Subjects}

Twelve healthy subjects (five male) aged between 21 and 47 yrs were recruited. All were healthy as determined from full medical history, physical examination and laboratory screening tests. Exclusion criteria included a history of drug abuse, heavy alcohol consumption, active
Division of Respiratory Medicine, City Hospital, Nottingham, UK

Correspondence: T.W. Harrison

Division of Respiratory Medicine

City Hospital

Hucknall Road

Nottingham NG5 1PB

UK

Fax: 441158404771

Keywords: Oral charcoal pharmacokinetics

salmeterol

Received: March 231998

Accepted after revision July 301998

This study was supported by GlaxoWellcome, Greenford, UK. smoking, regular medication during the four weeks prior to the study and an inability to use a metered-dose inhaler satisfactorily. Females of child-bearing age were required to be using adequate contraception and have a negative pregnancy test. Subjects gave informed written consent and the study was approved by the University of Nottingham Medical School Ethics Committee.

\section{Measurements}

Subjects were semi-recumbent for all pharmacodynamic measurements. Cardiac frequency $(f \mathrm{C})$ and $\mathrm{Q}-\mathrm{T}$ interval corrected for heart rate (QTc) were measured by 12-lead electrocardiography (Marquette MAC II, Marquette Electronics Inc., Milwaukee, WI, USA) programmed to calculate $f C$ and QTc interval from the mean of five successive $\mathrm{R}-\mathrm{R}$ intervals. $\mathrm{C} \mathrm{C}$, systolic and diastolic blood pressure were measured using a semi-automated sphygmomanometer (Narco Scientific BP203NA) with a standard width cuff. Venous blood samples were analysed in batches at the end of the study for plasma potassium concentrations by flame photometry (Olympus AU5000, Olympus Optical Co. Ltd, Eastleigh, UK) and plasma glucose concentrations by a hexokinase assay (Olympus AU800). 


\section{Protocol}

Subjects were given inhaled salmeterol $400 \mu \mathrm{g}$, inhaled salmeterol $400 \mu \mathrm{g}$ plus oral charcoal or inhaled placebo plus oral charcoal in a randomized three-way crossover study. The treatments with charcoal were double-blind, whilst that of salmeterol without charcoal was single-blind. The principal investigator left the study room when charcoal was scheduled and an independent investigator gave charcoal in water or just water to the subjects. Subjects refrained from strenuous exercise or alcohol for $24 \mathrm{~h}$ and from food and caffeinated beverages from midnight prior to each visit.

Subjects attended the department at the same time on three mornings at least $72 \mathrm{~h}$ apart. An intravenous cannula (Butterfly 21G; Abbot, Sligo, Ireland) was inserted into a forearm vein and maintained patent with heparinized saline, and an automated sphygmomanometer placed on the opposite arm. Subjects were attached to a 12-lead electrocardiograph (ECG). The ECG and blood pressure were recorded at 5-min intervals until stable baseline values were attained, defined as three consecutive readings of $f \mathrm{C}$ and blood pressure within 10 beats $\cdot \mathrm{min}^{-1}$ and $10 \mathrm{mmHg}$, respectively. Blood was taken on two occasions before dosing for baseline plasma potassium and glucose concentrations.

Subjects swallowed $5 \mathrm{~g}$ of activated charcoal suspended in $50 \mathrm{~mL}$ of water or water alone and 2 min later inhaled eight puffs of salmeterol (50 $\mu \mathrm{g} \cdot \mathrm{puff}^{-1}$ ) (GlaxoWellcome, Greenford, Middlesex, UK) or eight puffs of placebo from a metered-dose inhaler every $20 \mathrm{~s}$. The inhalers had the same specification as standard $25 \mu \mathrm{g}$ salmeterol metereddose inhalers. Metered-dose inhalers were primed prior to use and actuated as the patient breathed in from functional residual capacity (FRC) to vital capacity (VC) followed by a $10 \mathrm{~s}$ breath-hold. Further charcoal $(5 \mathrm{~g})$ or water was given 2 min after the final actuation of the inhaler followed by $10 \mathrm{~g}$ of charcoal in $100 \mathrm{~mL}$ of water or water alone at 60,120 and 180 min post-treatment, administered according to the methods of Borgstrom and NiLSSON [5] and validated for salmeterol by WARD et al. [4]. Timing was started immediately following the final inhalation and $f C$, QTc interval and blood pressure were measured and blood withdrawn in that order at intervals for the next $4 \mathrm{~h}$.

The study was to be stopped and oral propranolol $10 \mathrm{mg}$ given if intolerable symptoms occurred or if the $f C$ rose above 140 beats $\cdot \mathrm{min}^{-1}$. The study had $90 \%$ power to detect a difference of 10 beats. $\mathrm{min}^{-1}$ for $f \mathrm{C}$ and $85 \%$ power to detect a difference of $0.20 \mathrm{mmol} \cdot \mathrm{L}^{-1}$ for plasma potassium between any pair of treatments [1].

\section{Analysis}

A time-weighted mean response was calculated for each measurement. Comparisons were made by multifactorial analysis of variance using period, treatment and subjects as dependent variables. For significant effects, contrasts to assess the significance and size (95\% confidence intervals (CI)) of pairwise comparisons were fitted to the analysis of variance model using a SAS statistical package (SAS Institute, Cary, NC, USA).

\section{Results}

All 12 subjects completed the study. None of the baseline values showed a significant treatment or period effect (table 1).

Inhaled salmeterol $400 \mu \mathrm{g}$ whether given alone or with activated charcoal produced significant increases in $f C$, QTc interval and plasma glucose and a fall in plasma potassium when compared to placebo with charcoal (table 1, fig. 1). Activated charcoal attenuated the mean increase in $f \mathrm{C}$ and plasma glucose following salmeterol $400 \mu \mathrm{g}$ by 7.8 beats $\cdot \mathrm{min}^{-1}$ and $0.59 \mathrm{mmol} \cdot \mathrm{L}^{-1}$, respectively, equivalent to 28 and $36 \%$ of the total change observed. It also attenuated the effect of salmeterol on QTc interval by 7.7 $\mathrm{ms}(30 \%$ reduction) but this was not statistically significant. Its effects on plasma potassium concentration were minimal (table 1, fig. 1). No changes in systolic or diastolic blood pressure occurred with any treatment.

Table 1. - Baseline values (SD), time-weighted mean values (SEM) following each treatment and mean differences (95\% confidence intervals) between treatments for cardiac frequency $(f C), Q-T$ interval corrected for heart rate (QTc), plasma potassium and glucose concentrations

\begin{tabular}{|c|c|c|c|c|}
\hline & $\begin{array}{c}f \mathrm{C} \\
\text { beats } \cdot \mathrm{min}^{-1}\end{array}$ & $\begin{array}{l}\text { QTc } \\
\text { interval } \\
\mathrm{ms}\end{array}$ & $\begin{array}{l}\text { Plasma potassium } \\
\text { concentration } \\
\text { mmol } \cdot \mathrm{L}^{-1}\end{array}$ & $\begin{array}{c}\text { Plasma glucose } \\
\text { concentration } \\
\text { mmol } \cdot \mathrm{L}^{-1}\end{array}$ \\
\hline \multicolumn{5}{|l|}{ Baseline values } \\
\hline $\mathrm{P}$ and $\mathrm{C}$ & $68(6)$ & $404(15)$ & $3.77(0.20)$ & $5.11(0.63)$ \\
\hline $\mathrm{S}$ & $67(7)$ & 405 (14) & $3.74(0.25)$ & $5.56(1.43)$ \\
\hline $\mathrm{S}$ and $\mathrm{C}$ & $69(7)$ & $406(11)$ & $3.74(0.16)$ & $5.20(1.24)$ \\
\hline \multicolumn{5}{|c|}{ Time-weighted mean values following treatment } \\
\hline $\mathrm{P}$ and $\mathrm{C}$ & $63(1.6)$ & $404(3.6)$ & $3.74(0.05)$ & $5.13(0.17)$ \\
\hline $\mathrm{S}$ & $91(1.7)$ & $429(3.5)$ & $3.35(0.05)$ & $6.75(0.18)$ \\
\hline $\mathrm{S}$ and $\mathrm{C}$ & $84(1.7)$ & $422(3.6)$ & $3.39(0.05)$ & $6.17(0.17)$ \\
\hline \multicolumn{5}{|c|}{ Differences between treatment } \\
\hline $\mathrm{S}$ and $\mathrm{C}$ versus $\mathrm{P}$ and $\mathrm{C}$ & $\begin{array}{c}20.3 \\
(15-25)\end{array}$ & $\begin{array}{c}17.7 \\
(7-29)\end{array}$ & $\begin{array}{c}-0.35 \\
(-0.50-0.20)\end{array}$ & $\begin{array}{c}1.04 \\
(0.52-1.55)\end{array}$ \\
\hline $\mathrm{S}$ versus $\mathrm{P}$ and $\mathrm{C}$ & $\begin{array}{c}28.1 \\
(23-33)\end{array}$ & $\begin{array}{c}25.5 \\
(14-37)\end{array}$ & $\begin{array}{c}-0.40 \\
(-0.54-0.25)\end{array}$ & $\begin{array}{c}1.62 \\
(1.06-2.19)\end{array}$ \\
\hline $\mathrm{S}$ versus $\mathrm{S}$ and $\mathrm{C}$ & $\begin{array}{c}7.8 \\
(2-13)\end{array}$ & $\begin{array}{c}7.7 \\
(-3-19)\end{array}$ & $\begin{array}{c}-0.04 \\
(-0.19-0.11)\end{array}$ & $\begin{array}{c}0.59 \\
(0.04-1.13)\end{array}$ \\
\hline
\end{tabular}

S: salmeterol; C: activated charcoal; P: placebo. 

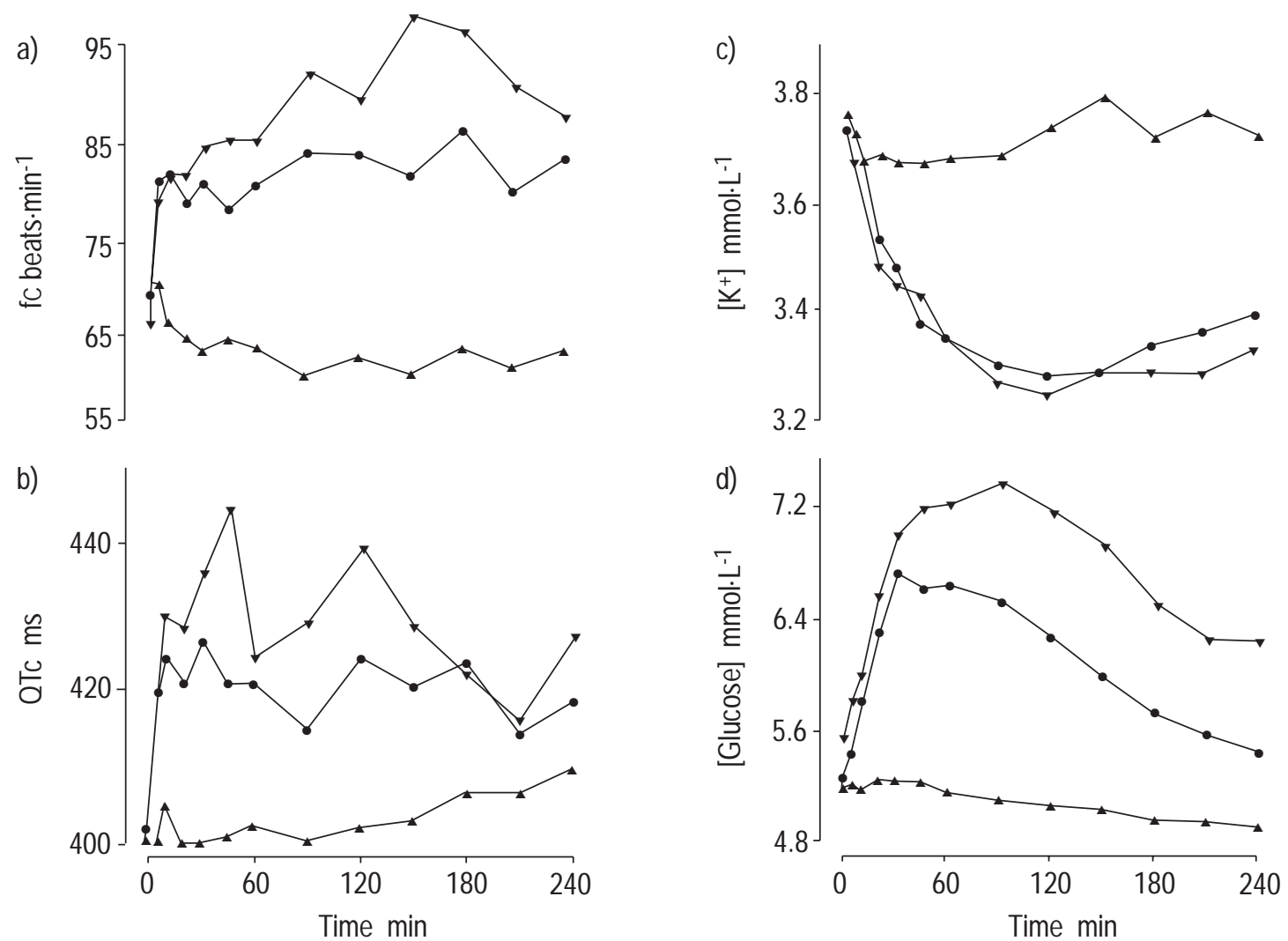

Fig. 1. - Mean values of a) cardiac frequency $(f \mathrm{C})$, b) Q-T interval corrected for heart rate (QTc), c) plasma potassium and d) glucose concentrations for placebo $(\boldsymbol{\Delta})$, salmeterol $(\boldsymbol{\nabla})$ and salmeterol with activated charcoal $(\bullet)$ over $4 \mathrm{~h}$.

\section{Discussion}

It was shown that activated charcoal produces significant attenuation of the $f C$ and glucose responses to salmeterol $(400 \mu \mathrm{g})$ administered by a metered-dose inhaler. A high-dose of salmeterol was given, four-fold greater than the highest recommended dose, because it produced a large systemic effect in a previous study [3] and thus would enable the determination of the effect of adding activated charcoal.

Activated charcoal inhibited the $f \mathrm{C}$ and glucose response to inhaled salmeterol by 28 and $36 \%$, respectively. The reason why activated charcoal had little effect on the plasma potassium response compared with plasma glucose and $f \mathrm{C}$ following inhaled salmeterol is unclear since all would be expected to reflect differences in bioavailability. It may be that the lack of effect on serum potassium concentration was a spurious finding or the fall in plasma potassium concentration may have reached a plateau due to maximum stimulation of skeletal muscle $\mathrm{Na}^{+} / \mathrm{K}^{+}$adenosine triphosphatase (ATPase) by salmeterol. Similar falls in plasma potassium concentration have been recorded in previous $\beta_{2}$-agonist studies [1-3, 6-8], but whether a plateau had occurred is uncertain.

Oral activated charcoal has been shown to block gastrointestinal absorption of terbutaline [5] and it completely attenuated the systemic responses to oral salmeterol 500 $\mu \mathrm{g}$ in a study of similar design to the present study [4]. It is postulated, therefore, that the reduction in $f \mathrm{C}$ and glucose responses to salmeterol of $28-36 \%$ when salmeterol was given with activated charcoal, represents the relative gastrointestinal bioavailability of salmeterol when administered by a metered-dose inhaler without a spacer device. These values compare to a contribution to systemic effects of roughly $20 \%$ for the swallowed fraction of an inhaled dose of salbutamol delivered by a metered-dose inhaler in previous studies $[6,9]$ although there are no direct comparisons between the two drugs.

The finding that most of the systemic effects from a high-dose of inhaled salmeterol are due to the inhaled rather than the swallowed fraction suggests that differences in gastrointestinal absorption between salmeterol and salbutamol are not a major determinant of differences in systemic effects.

Acknowledgements. The authors thank S. Lewis for statistical support and C. Man, F. House and J. Ward for technical support.

\section{References}

1. Smyth ET, Pavord ID, Wong CS, Wisniewski AF, Williams J, Tattersfield AE. Interaction and dose equivalence of salbutamol and salmeterol in patients with asthma. $\mathrm{Br}$ Med J 1993; 306: 543-545.

2. Bennett JA, Smyth ET, Pavord ID, Wilding PJ, Tattersfield AE. Systemic effects of salbutamol and salmeterol in patients with asthma. Thorax 1994; 49: 771-774.

3. Bennett JA, Tattersfield AE. Time course and relative dose potency of systemic effects from salbutamol and salmeterol in healthy subjects. Thorax 1997; 52: 458-464. 
4. Ward JK, Man CY, Horton J, Vantresca GP. Systemic dynamic responses to oral doses of salmeterol in healthy subjects - effect of activated charcoal. Am J Respir Crit Care Med 1997; 155: A346.

5. Borgstrom L, Nilsson M. A method for determination of the absolute pulmonary bioavailability of inhaled drugs: terbutaline. Pharm Res 1990; 7: 1068-1070.

6. Newnham DM, McDevitt DG, Lipworth BJ. Comparison of the extrapulmonary $\beta_{2}$-adrenoreceptor responses and pharmacokinetics of salbutamol given by standard metered dose inhaler and modified actuator device. Br J Clin Pharmacol 1993; 36: 445-450.
7. Wong CS, Pavord ID, Williams I, Britton JR, Tattersfield AE. Bronchodilator cardiovascular, and hypokalaemic effects of fenoterol, salbutamol, and terbutaline in asthma. Lancet 1990; 336: 1396-1399.

8. Windom HH, Burgess CD, Siebers RW, et al. Pulmonary and extra pulmonary effects of inhaled $\beta$-agonists in patients with asthma. Clin Pharmacol Ther 1990; 48: 296-301.

9. Collier JG, Dobbs RJ, Williams I. Salbutamol aerosol causes a tachycardia due to the inhaled rather than the swallowed fraction. Br J Clin Pharmacol 1980; 9: 273274. 